\title{
Measuring Gender Identity and Religious Identity with Adapted Versions of the Multigroup Ethnic Identity Measure-Revised
}

\author{
Brien K. Ashdown ${ }^{1}$, Natalie Homa ${ }^{2}$ \& Carrie M. Brown ${ }^{3}$ \\ ${ }^{1}$ Hobart and William Smith Colleges, Geneva, New York, USA \\ ${ }^{2}$ Doane College, Crete, Nebraska, USA \\ ${ }^{3}$ Agnes Scott College, Decatur, Georgia, USA \\ Correspondence: Brien K. Ashdown, Department of Psychology, Hobart and William Smith Colleges, Geneva, \\ NY 14456, USA. E-mail: ashdown@hws.edu
}

Received: November 10, 2013

Accepted: March 24, 2014

Online Published: April 23, 2014

doi:10.5539/jedp.v4n1p226

URL: http://dx.doi.org/10.5539/jedp.v4n1p226

Part of this article represents a portion of the doctoral dissertation of the first author. The authors wish to acknowledge and thank Drs. Judith L. Gibbons, Kimberly K. Powlishta, Richard D. Harvey and Lisa Willoughby for their help with this manuscript.

\begin{abstract}
Adolescent identity develops across various domains (e.g., ethnicity, gender, religion). Although these domains share elements of identity (e.g., belongingness, self-categorization) there is a lack of continuity in the elements selected when measuring various domains of adolescent identity. This study tested whether an adapted version of Phinney and Ong's (2007) Multigroup Ethnic Identity Measure-Revised (developed to measure adolescents' ethnic identity) could also measure gender and religious identities. Participants $\left(N=247,56 \%\right.$ female, $M_{\text {age }}=$ 13.33 years) completed adapted versions of the MEIM - R measuring gender identity (which we call the Multi-Identity Measure for Gender) and religious identity (Multi-Identity Measure for Religion). Confirmatory factor analysis models for the MIM-Gender and MIM-Religion scales demonstrated modest to good fits. In addition, the MIM-Gender and MIM-Religion scales demonstrated preliminary validity. These preliminary results suggest the adapted MEIM $-\mathrm{R}$ scales have the potential to measure domains of adolescent identity beyond ethnicity.
\end{abstract}

Keywords: ethnic identity, gender identity, religious identity, identity measurement, MEIM-R, preliminary psychometrics

\section{Introduction}

Adolescence has long been recognized as an important period for identity and its development (e.g., Erikson, 1950; Marcia, 1980). Adolescents work to establish a clear worldview and determine how they fit into the different social groups around them. Meeus (2011) recently published a review of longitudinal research focusing on adolescent identity. His review demonstrated that while different types of identity develop at different rates, adolescence remains a vital time in life for people to search for and establish their identities (Phillips, 2008). This identity development occurs across various domains, due to the fact that there are so many types of social groups with which people can identify (social identity theory; Tajfel \& Turner, 1986). These groups include religious (Smith, 2007), gender (Hill \& Lynch, 1983; Powlishta, 2004), ethnic (Aboud \& Doyle, 1993; Phinney, 1992), and sexual orientation (Diamond \& Butterworth, 2008; Diamond, Pardo, \& Butterworth, 2011; Dillon, Worthington, \& Moradi, 2011), as well as a number of others. In this paper, we will focus on ethnic group, gender group, and religious group identities.

It has been suggested that the domains of group identities (e.g., religious, gender, ethnic) all share similar elements. For example, Ashmore, Deaux and McLaughlin-Volpe (2004) suggested that, in general, group identities contain emotional and evaluative elements such as interdependence and attachment (i.e., the level of emotional involvement with one's group), evaluation (i.e., the attitude one has toward the group), content and meaning (i.e., the meaning that group membership gives to one's self-concept), and centrality (i.e., how important the group membership is to one's overall self-concept). In addition, group identities contain behavioral 
elements such as self-categorization (i.e., labeling oneself as a group member), behavioral involvement (i.e., participation in activities valued by the group), and social embeddedness (i.e., the degree to which group membership plays a role in one's social life). Others have suggested similar elements, such as belongingness (Tajfel \& Turner, 1986) and security (Roberts et al., 1999).

As just one domain-specific example, recent research particular to gender identity has suggested similar identity elements. Egan and Perry (2001) have suggested using self-selected gender categories (i.e., gender groups) as a way to explore gender identity among adolescents. Others have suggested that gender identity is composed of various dimensions, such as centrality, gender typicality, gender category knowledge (Tobin et al., 2010), as well as self-selected gender categories (Diamond \& Butterworth, 2008; Egan \& Perry, 2001). This research suggests that when discussing group identity in general (Ashmore et al., 2004) or within a specific domain-such as gender (Tobin et al., 2010), ethnicity, or religion - the concept of group identity is composed of various, similar elements (for a review, Perry \& Pauletti, 2011).

While similar research on religious identity does not exist as it does for gender identity, based on the theoretical basis of group identity proposed by researchers such as Tajfel and Turner (1986) and Ashmore et al. (2004), one can hypothesize that a person's religious identity will incorporate the same theoretical concepts. For example, constructs such as interdependence, attachment, evaluation, content and meaning, centrality, self-categorization, and social embeddedness will all influence an individual's religious group identity - much as it does gender group and ethnic group identity (Ashmore et al., 2004; Roberts et al., 1999; Tajfel \& Turner, 1986).

Although there may be continuity in the elements shared by the domains of group identities as discussed above, there is a lack of continuity in the elements selected when measuring group identities. For example, some methods simply rely on the element of self-categorization by asking research participants to mark a box that indicates the ethnic, gender, or religious group with which they identify (Burton, Nandi, \& Platt, 2010). Recently, in an attempt to acknowledge the issue of mixed identities (e.g., those who make a claim to two or more ethnicities), Gibbons and Ashdown (2010) developed a way to measure (ethnic) identity by asking participants to place a mark on a line between two ethnicities in order to allow the participants to claim a mixed identity. Some researchers measure group identity by exploring involvement in group related activities, such as asking participants how often they attend religious services and using that as a measure of the behavioral involvement element of religious group identity (Ashdown, Hackathorn, \& Clark, 2011; Hill \& McCullough, 2008) or level of commitment to a group (e.g., Leak, 2009). Still, others measure people's identity via open-ended interviews or questions (e.g., Cohen-Malayev, Assor, \& Kaplan, 2009; Hunsberger, Pratt, \& Pancer, 2001). Finally, some use people's attitudes about their own and other groups as measurements of the evaluation element of identity (Williams, Best, \& Boswell, 1975).

With such varying methods available to measure group identity, it can be difficult, if not impossible, to compare adolescents' identity across different types of groups. For example, with no general measurement of group identity, it would be difficult to compare an adolescent's identity in one realm (such as gender or religion) with his or her identity in another realm (such as ethnicity) because different types of group identity are often measured in very different ways, with different elements of group identity being examined.

Some scales exist that measure identity across multiple domains such as the Extended Objective Measure of Ego Identity-II (Bennion \& Adams, 1986) and the Ego Identity Process Questionnaire (Balistreri, Busch-Rossnagel, $\&$ Geisinger, 1995), among others. These domains often involve ideological (e.g., political, religion, occupation, values) and interpersonal (e.g., friendships, dating, gender roles, family) domains. However, typically these scales are coded to identify an overall identity status (i.e., achievement, moratorium, diffusion, foreclosure). In addition, these scales are somewhat lengthy (26-64 items). A brief tool that could indicate the level of group identification in various domains will aid future studies of adolescent identity.

\subsection{A Possible Solution: The Multigroup Ethnic Identity Measure-Revised}

The utilization of Phinney and Ong's (2007) Multigroup Ethnic Identity Measure-Revised (MEIM-R) as a way to measure not only adolescents' ethnic identity, but also other types of group identity, presents a psychometric possibility. The original Multigroup Ethnic Identity Measure, or MEIM (Phinney, 1992), was designed to meet the need for a measure that could assess adolescent ethnic identity across ethnic groups (for example, participants are asked to respond to the prompt "I have a lot of pride in my ethnic group"). Subsequent research (Roberts et al., 1999; Spencer, Icard, Harachi, Catalano, \& Oxford, 2000; Yancey, Aneshensel, \& Driscoll, 2003) suggested that rather than creating classifications of identity status, the MEIM could best be conceptualized as consisting of two elements - exploration and commitment, which is consistent with social identity theory (Tajfel \& Turner, 1986) and the work of Marcia (1980). Additional research (Phinney \& Ong, 
2007) worked toward revising the MEIM, which resulted in the Multigroup Ethnic Identity Measure- Revised (MEIM-R), a six-item tool with three items measuring exploration and three items measuring commitment. Based on a test of competing models, Phinney and Ong (2007) confirmed that the MEIM-R is best represented as a correlated two-factor model-one factor measuring identity exploration, the other measuring identity commitment. Hence, in a theoretical model based on MEIM-R, group identity (whether it be gender group, religious group or ethnic group) is defined as the extent to which individuals have explored and committed to a particular group identity.

Recently, the original twelve-item MEIM (Phinney, 1992) has been modified to measure American identity (Schwartz et al., 2012). By modifying the original wording of the MEIM to explore American identity (e.g., replacing the words "my ethnic group" with the words "the United States"), Schwartz and colleagues were able to demonstrate that the basis of the original MEIM could be expanded to measure group identities other than ethnicity, particularly when group identity is defined using the constructs of exploration and commitment. The modified MEIM (which the authors called the American Identity Measure, or AIM) had a similar two-factor construct (i.e., exploration and commitment) as the original MEIM, suggesting the possibility that the MEIM-R is also modifiable and useful in measuring other types of group identities utilizing this same theoretical framework.

\subsection{Purpose of Study}

The purpose of our study is to take the initial, preliminary steps in exploring the psychometric properties of adapted MEIM-R scales in regards to group identity in two domains other than ethnicity: gender identity and religious identity. Specifically, we assess the fit of the theoretically and empirically driven two factor model representing exploration and commitment, and we also assess the two adapted MEIM-R scales for preliminary validity. For clarity and future use, we refer to the MEIM-R adapted to measure exploration and commitment in regards to gender identity as the Multi-Identity Measure for Gender (MIM-Gender), and the MEIM-R adapted to measure exploration and commitment regarding religious identity as the Multi-Identity Measure for Religion (MIM-Religion). Similar to Schwartz et al. (2012), this will be done by conducting confirmatory factor analyses on participants' scores on the MEIM-R, the MIM-Religion, and the MIM-Gender in order to determine if the structures of the revised measures statistically match the structure of the original measure as reported by Phinney and Ong (2007).

\section{Method}

\subsection{Participants}

The sample consisted of 247 ( $56 \%$ female) early ( $\mathrm{n}=122$; ages $10-12$ years), middle ( $\mathrm{n}=65$; ages $13-15$ years), and late $(\mathrm{n}=60$; ages $16-18$ years $)$ adolescents with a mean age of $13.33(S D=2.68)$. The majority of the participants self-categorized as Caucasian (86\%), with the remaining participants identifying as Hispanic (3\%), Black $(3 \%)$, Asian $(2 \%)$, and mixed heritage or other $(6 \%)$. The majority of the participants identified as Christian (72\%), with the remaining participants self-categorizing as Muslim (6\%), Atheist (4\%), and other $(18 \%)$.

\subsection{Measures}

\subsubsection{Group Identity}

The participants completed versions of the MEIM-R (Phinney \& Ong, 2007) three times. To measure participants' ethnic identity, we used the original MEIM-R. To measure participants' gender identity and religious identity, we used modified versions of the MEIM-R (i.e., MIM-Gender and MIM-Religion; see Table 1 for the modified wording). For all three versions, participants rated the items from $1=$ disagree a lot to $5=$ agree a lot. For the MEIM-R, the overall Cronbach's alpha was .82 (with an alpha of .75 for the exploration item scores and .74 for the commitment item scores). These alpha levels are similar to those found in Phinney and Ong's (2007) study. In their study, the MEIM — R's exploration item scores had an alpha of .76, the commitment item scores had an alpha of .78, and the overall MEIM-R alpha was .81. In our study, the MIM-Gender had a Cronbach's alpha of .77 (with an alpha of .76 for the exploration item scores and .72 for the commitment item scores) and the MIM-Religion had a Cronbach's alpha of .91 (with an alpha of .85 for the exploration item scores and .85 for the commitment item scores). 
Table 1. MEIM-R items with adapted MIM-Gender and MIM-Religion phrases in parentheses

\begin{tabular}{ll}
\hline Commitment Items & Exploration Items \\
\hline $\begin{array}{l}\text { 1. "I have a strong sense of belonging to my ethnic } \\
\text { group (gender group, religious group)." }\end{array}$ & $\begin{array}{l}\text { 1. "I have spent time trying to find out more about } \\
\text { being a member of my ethnic group (gender group, } \\
\text { religious group) such as its history, traditions, and } \\
\text { customs." }\end{array}$ \\
$\begin{array}{ll}\text { 2. "I understand pretty well what it means to be a } \\
\text { member of my ethnic group (gender group, religious } \\
\text { group)." }\end{array}$ & $\begin{array}{l}\text { understand what it means to be a member of my ethnic } \\
\text { group (gender group, religious group) better." }\end{array}$ \\
$\begin{array}{ll}\text { 3. "I feel a strong attachment towards my own ethnic } \\
\text { group (gender group, religious group)." }\end{array}$ & $\begin{array}{l}\text { 3. "I have often talked to other people in order to learn } \\
\text { more about my ethnic group (gender group, religious } \\
\text { group)." }\end{array}$
\end{tabular}

\subsubsection{Group Attitudes}

Participants assigned descriptive traits to members of distinct social groups within each of the three domains. At the top of each piece of paper in the survey packet was a description of a person (i.e., an average African American individual, an average Christian individual). Following the description of the person was a list of various trait descriptors (i.e., unselfish, coward). A list of traits from the Adjectives Check List (Williams \& Best, 1982) that are not linked to gender or ethnicity were piloted to determine which were seen as positive and which are seen as negative. The six most negative traits and the six most positive traits were then included in the survey. See Appendix A for a list of these twelve traits.

Participants were asked to rate the twelve traits for eleven different people such that they provided 132 different ratings. The survey packets they received had a piece of paper asking for ratings for each of the following: four ethnic group members [a Caucasian (White) American, an Asian American, a Hispanic American, and an African American], both genders (a male and a female), and five religious group members (a Jew, a Muslim, a Christian, an atheist, and their own specific church). They were asked to rate how well each trait pertained to the described person on a 5-point Likert scale. Responses ranged from "never describes this person" to "always describes this person." Participants who did not indicate their own ethnicity or religion were not included in the analyses that were computed for that variable.

After data collection, the ratings on these traits were used to create various measures of group bias. First, because we are exploring group identity and bias in a general sense, we collapsed ethnic, religious, and gender groups to create an in-group and an out-group for each participant in each domain. In other words, each participant had an ethnic in-group and out-group, a gender in-group and out-group, and a religious in-group and out-group. For example, an Asian American participant's ethnic in-group would be Asian Americans, and his or her ethnic out-group would be a combined group of Caucasian Americans, African Americans, and Hispanic Americans.

We averaged participants' ratings for each group to create two variables for each group: an average rating on the positive traits and an average rating on the negative traits. For example, an average positive rating for African Americans and an average negative rating for African Americans were created for each participant, regardless of group membership. Then, based on the participants' group membership, we combined the average ratings for each of the participants' out-groups (in each respective domain) to create an average out-group rating on the positive traits and an average out-group rating on negative traits. Lastly, we used the ratings on the traits for the in-group (again, for each respective domain) in the same manner to create two variables: a positive in-group rating and a negative in-group rating. In this way, each participant had an average score for negative out-group ratings, positive out-group ratings, negative in-group ratings, and positive in-group ratings for each of the three domains.

\subsection{Procedure}

The measures described above were part of a larger packet of surveys that participants completed. The participants responded to the identity measures before responding to the other questionnaires. In order to verify that all participants would be able to comprehend the questions in the survey packets, the wording of all questions and instructions were checked for reading comprehension level using Microsoft Word software. This ensured that the entire packet was not above a fifth-grade reading level. In addition, the survey packet was piloted to establish that the reading level of the survey items was appropriate, which it was. 
After receiving permission from the appropriate Institutional Review Board, and in order to create a sample consisting of the full range of adolescence, we recruited potential participants from public school districts and a private university in the same metropolitan area in the Midwestern United States. After schools granted us permission to recruit participants, consent forms were sent home to parents of minor children. Three to five days after consent forms were sent home, participants who had received parental permission to participate were approached in a classroom setting, where the research was explained to them and they were asked to participate. Only children who had parental permission and who gave their own assent were allowed to participate. For the youngest participants, a member of the research team was in the room to help guide participants through the survey packet. He read the first few items of each scale aloud with the participants to help them understand the instructions. They were then allowed to finish the scale on their own, with the investigator present to answer any questions. Older participants were given the survey packet and allowed to work through it at their own pace, with someone available to answer any questions.

Only participants in the university sub-sample were compensated for their participation in the study - they received partial credit toward a requirement to participate in psychological research studies as introductory level students. All other participants participated without compensation after school district superintendents, school principals, and parents provided permission for the children's participation. Most participants completed the survey in 30-45 minutes, with all participants completing the survey within 60 minutes.

\section{Results}

To examine the relationship between the theoretical structure of group identity and the structural models of the modified scales that measure adolescents' gender and religious identities, we conducted confirmatory factor analyses in AMOS 18 employing the Maximum Likelihood Estimation method. We also conducted confirmatory factor analyses for the MEIM-R's measurement of ethnic identity (the original version of the MEIM-R), in order to test whether we could replicate the structure of the original instrument (Phinney \& Ong, 2007). We assessed model fit using criteria established by Kline (2005) and Hu and Bentler (1995). A good model fit is characterized by Chi-square $p>.05$, AGFI, IFI, and CFI greater than .95, as well as RMSEA and SRMR less than .05. An acceptable model fit includes AGFI, IFI, and CFI greater than .90 and RMSEA and SRMR less than .10. These fit criteria are the same as those chosen by Phinney and Ong (2007).

Before conducting the confirmatory factor analyses, we screened the data for normality and outliers. An examination of Mahalanobis distance statistic revealed no outliers. However, assessment of skew and kurtosis scores revealed slightly non-normal data for several variables. Mardia's coefficient of multivariate normality also revealed somewhat non-normal data: ethnic $=5.06$; gender $=15.59$; religious $=29.55$. Because the data did not meet the assumption of normality, we applied a Maximum Likelihood bootstrap procedure in the analysis of the three measurement models.

The following three a priori confirmatory factor analysis (CFA) models for ethnic identity were examined attempting to replicate the findings of Phinney and Ong (2007): one factor, uncorrelated two factors, and correlated two factors. Table 2 shows that the correlated two factor model fit the data better than the alternative models. Specifically, the three commitment items loaded onto one factor and the three exploration items loaded onto a second factor. The six items loaded onto the two factors (i.e., commitment and exploration) in the medium to high range (.55 to .78$)$. Although this model's Chi-square value was significant, evaluation of other indices of model fit revealed a good fitting model (see Table 2). Figure 1 shows the model details, including the correlation between the exploration and commitment factors. The fit indices and reliability coefficients closely reflected the findings of Phinney and Ong (2007) as shown in Table 2. A single second-order factor model was not conducted because, statistically speaking, it is not advised to carry out a second-order model with only two first-order factors (i.e., exploration and commitment; Kline, 2010). 
Table 2. Fit indices of Confirmatory Factor Analyses (Maximum Likelihood Estimation) of MEIM-R items compared to Phinney and Ong (2007)

\begin{tabular}{lllllllll}
\hline Model & $\chi^{2}$ & $d f$ & $\chi^{2} / d f$ & AGFI & SRMR & RMSEA & IFI & CFI \\
\hline One factor & $53.08^{* *}$ & 9 & 5.90 & .84 & .06 & .14 & .91 & .90 \\
(Phinney \& Ong, 2007) & $(74.08)$ & $(9)$ & $(8.23)$ & $(.85)$ & $(.16)$ & $(.09)$ & $(.95)$ & $(.91)$ \\
Uncorrelated two factors & $123.56^{* *}$ & 9 & 13.73 & .72 & .26 & .23 & .75 & .75 \\
& $(96.55)$ & $(9)$ & $(10.73)$ & $(.81)$ & $(.36)$ & $(.23)$ & $(.85)$ & $(.87)$ \\
Correlated two factors & $23.84^{*}$ & 8 & 2.98 & .92 & .04 & .09 & .97 & .97 \\
& $(15.29)^{* *}$ & $(8)$ & $(1.91)$ & $(.96)$ & $(.05)$ & $(.04)$ & $(.98)$ & $(.98)$ \\
\hline
\end{tabular}

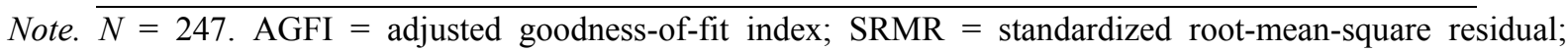
RMSEA = root-mean-square error of approximation; IFI = incremental fit index; CFI = comparative fit index. Phinney and Ong (2007) results in parentheses for comparison; Phinney and Ong's (2007) $\chi^{2}$ computations were also significant. $* p<.01 . * * p<.001$.

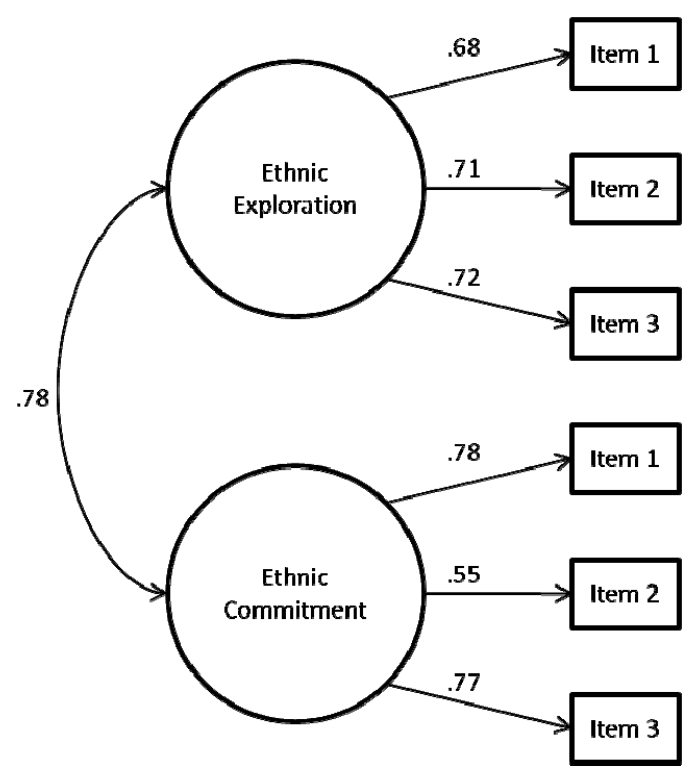

Figure 1. Standardized parameter estimates of a Two-Factor Model of Ethnic Identity as measured by the MEIM-R

Note. Item numbers refer to the items from the scale shown in Table 1.

After conducting the CFA of the MEIM- R (for ethnic identity), we evaluated the adapted MEIM-R scales. All three CFA models were assessed to test the fit of the MIM-Gender and MIM-Religion scales; however, the two-factor correlated model was the best fit model empirically and theoretically - mirroring the findings of Phinney and Ong (2007) - and thus will be the focus of this report (however, results of the one factor models and uncorrelated two factor models can be seen in Table 3). For gender identity, the six items loaded onto the two factors (i.e., commitment and exploration) in the medium to strong range (.60 to .91). Again, the model's Chi-square value was significant, but other fit indices revealed a good fitting model (see Table 3). Figure 2 shows the model details, including the correlation between the exploration and commitment factors of gender identity. 
Table 3. Fit Indices of Confirmatory Factor Analyses (Maximum Likelihood Estimation) of MIM-Gender and MIM-Religion items

\begin{tabular}{|c|c|c|c|c|c|c|c|c|c|}
\hline & Model & $\chi^{2}$ & $d f$ & $\chi^{2} / d f$ & AGFI & SRMR & RMSEA & IFI & CFI \\
\hline \multirow{3}{*}{ MIM-Gender } & One factor & $138 * *$ & 9 & 15.33 & .60 & .11 & .24 & .71 & .70 \\
\hline & $\begin{array}{l}\text { Uncorrelated two } \\
\text { factors }\end{array}$ & $59.6^{* *}$ & 9 & 6.62 & .84 & .18 & .15 & .89 & .88 \\
\hline & Correlated two factors & $25.30 *$ & 8 & 3.16 & .91 & .05 & .09 & .96 & .96 \\
\hline \multirow{3}{*}{ MIM-Religion } & One factor & $43.2 * *$ & 9 & 4.8 & .87 & .03 & .12 & .96 & .96 \\
\hline & $\begin{array}{l}\text { Uncorrelated two } \\
\text { factors }\end{array}$ & $256.05 * *$ & 9 & 28.45 & .58 & .40 & .33 & .73 & .73 \\
\hline & Correlated two factors & $23.21^{*}$ & 8 & 2.90 & .91 & .02 & .09 & .98 & .98 \\
\hline
\end{tabular}

Note. $N=247$. AGFI $=$ adjusted goodness-of-fit index; SRMR $=$ standardized root-mean-square residual; RMSEA $=$ root-mean-square error of approximation; IFI $=$ incremental fit index; CFI = comparative fit index. * $p<.01 . * * p .001$

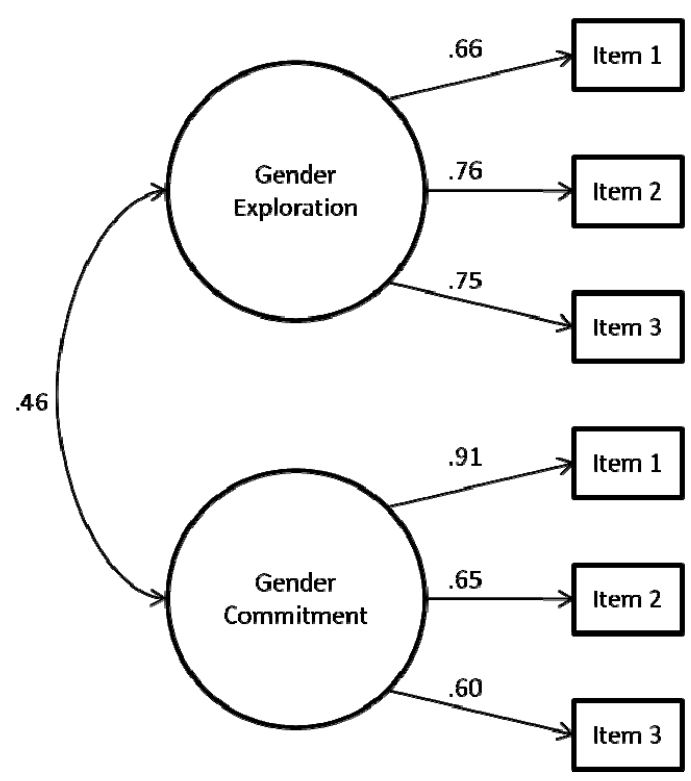

Figure 2. Standardized parameter estimates of a Two-Factor Model of Gender Identity as measured by the MIM-Gender

Note. Item numbers refer to the items from the scale shown in Table 1.

The final correlated two factor CFA model assessed the fit of the MIM-Religion, used to assess religious identity. The six items loaded onto the two correlated factors (i.e., commitment and exploration) in the medium to strong range (.78 to .89$)$. Although this model's Chi-square value was significant, evaluation of other indices of model fit revealed a good fitting model (see Table 3 ). Figure 3 shows the model details, including the strong correlation between the exploration and commitment of gender identity. 


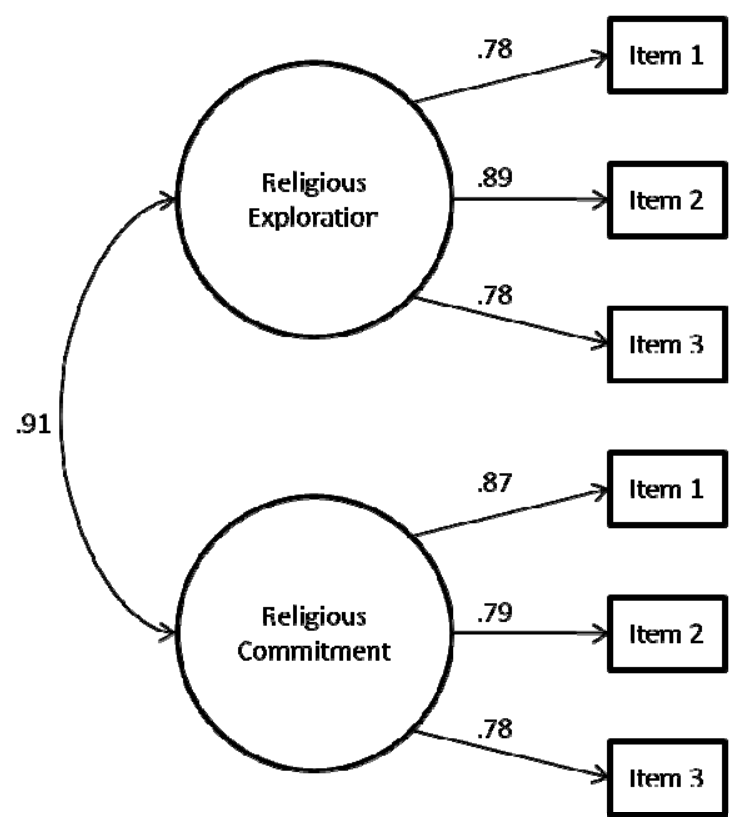

Figure 3. Standardized parameter estimates of a Two-Factor Model of Religious Identity as measured by the MIM-Religion

Note. Item numbers refer to the items from the scale shown in Table 1.

To examine the preliminary validity of the MIM-Gender and MIM-Religion, we computed correlations between the three different scales' scores (i.e., gender, religion, and ethnicity). Because of the high number of correlations computed, care should be taken when interpreting the significant results, and a Bonferroni correction for alpha levels should be utilized. As such, while correlations significant at the .05 and the .01 level are indicated in the correlation table (Table 4), an appropriate Bonferroni-corrected alpha level for the correlations would be .01. Participants' scores were correlated on the MEIM-R and MIM-Gender, MEIM-R and MIM-Religion, as well as MIM-Gender and MIM-Religion. These correlations suggest that participants with a stronger identification in one domain of identity also have stronger identification in the other two domains.

To further examine the validity of the MIM-Gender and MIM-Religion, we computed correlations between scores on the MEIM-R, MIM-Gender, and MIM-Religion and their respective group attitude composite scores. For example, scores on the MEIM-R were correlated to ethnic in-group positive ratings $(r=.22, p<.01)$; scores on the MIM-Religion were correlated with religious in-group positive ratings $(r=.23, p<.01)$; finally, scores on the MIM-Gender were correlated with gender in-group positive ratings $(r=.19, p<.01)$. See Table 4 for the complete correlation matrix. These correlations add strength to the validity of using an adapted MEIM-R to measure identity in different domains as, according to Social Identity Theory (Tajfel \& Turner, 1986), participants who were more strongly identified with the in-group also tended to see the in-group more positively 
Table 4. Correlation matrix of MEIM-R, MIM-Gender, MIM-Religion, and Group Attitudes in three domains

\begin{tabular}{|c|c|c|c|c|c|c|c|c|c|c|c|c|c|c|c|}
\hline & Ethnic & Gender & Religion & Ethnic & Ethnic & Ethnic & Ethnic & Gender & Gender & Gender & Gender & Religion & Religion & Religion & Religion \\
\hline & MEIM & MEIM & MEIM & In + & In - & Out + & Out - & In + & In - & Out + & Out - & In + & In - & Out + & Out - \\
\hline Ethnic MEIM & - & $.40^{* *}$ & $.46^{* *}$ & $.22 * *$ & -.11 & $.13 *$ & .00 & $.17^{* *}$ & -.12 & $.14^{*}$ & -.07 & $.12 *$ & -.09 & .02 & .07 \\
\hline Gender MEIM & & - & $.37 * *$ & .11 & -.12 & .08 & -.11 & $.19 * *$ & $-.13^{*}$ & -.01 & -.08 & .04 & -.06 & .00 & -.06 \\
\hline Religion MEIM & & & - & $.16^{* *}$ & -.05 & .08 & -.04 & $.17^{* *}$ & -.05 & .03 & .03 & $.23 * *$ & $-.15^{*}$ & -.06 & .10 \\
\hline Ethnic In + & & & & - & $-.24 * *$ & $.67^{* *}$ & -.06 & $.65^{* *}$ & $-.12 *$ & $.61^{* *}$ & -.09 & $.50^{* *}$ & $-.18^{* *}$ & $.54 * *$ & .04 \\
\hline Ethnic In - & & & & & - & -.12 & $.47^{* *}$ & $-.16^{*}$ & $.55^{* *}$ & -.12 & $.50^{* *}$ & -.07 & $.44^{* *}$ & -.07 & $.35^{* *}$ \\
\hline Ethnic Out + & & & & & & - & $-.32 * *$ & $.53^{* *}$ & $-.12 *$ & $.60^{* *}$ & $-.17^{*}$ & $.33 * *$ & -.06 & $.65^{* *}$ & $-.20 * *$ \\
\hline Ethnic Out - & & & & & & & - & -.06 & $.43^{* *}$ & -.17 & $.50^{* *}$ & -.05 & $.38^{* *}$ & $-.18^{* *}$ & $.67^{* *}$ \\
\hline Gender In + & & & & & & & & - & $-.36^{* *}$ & $.54^{* *}$ & .00 & $.51^{* *}$ & $-.14^{*}$ & $.47^{* *}$ & .02 \\
\hline Gender In - & & & & & & & & & - & $-.14^{*}$ & $.29^{* *}$ & -.12 & $.45^{* *}$ & -.08 & $.33^{* *}$ \\
\hline Gender Out + & & & & & & & & & & - & $-.25 * *$ & $.37 * *$ & -.09 & $.53^{* *}$ & .01 \\
\hline Gender Out - & & & & & & & & & & & - & .05 & $.28^{* *}$ & -.10 & $.42^{* *}$ \\
\hline Religion In + & & & & & & & & & & & & - & $-.49^{* *}$ & $.38^{* *}$ & .02 \\
\hline Religion In - & & & & & & & & & & & & & - & -.11 & $.35^{* *}$ \\
\hline Religion Out + & & & & & & & & & & & & & & - & $-.38^{* *}$ \\
\hline Religion Out - & & & & & & & & & & & & & & & - \\
\hline
\end{tabular}

Note. In + indicates in-group positive ratings; In - indicates in-group negative ratings; Out + indicates out-group positive ratings; Out - indicates out-group negative ratings. ${ }^{*} \mathrm{p}<.05 ;{ }^{* *} \mathrm{p}<.01$. Due to the high number of correlations, a Bonferroni-corrected alpha level of $p<.01$ is suggested when examining results.

\section{Discussion}

Our study set out to take initial, preliminary steps in exploring the psychometric properties of adapted MEIM-R scales to measure adolescents' gender identity (MIM-Gender) and religious identity (MIM-Religion), utilizing the theoretical constructs of commitment and exploration. Confirmatory factor analysis correlated two factor models for gender identity and religious identity demonstrated modest to good fits and provided evidence for the use of the MEIM-R to measure not only adolescents' ethnic identity exploration and commitment but also their gender identity and religious identity exploration and commitment. Participants' responses to the same items loaded onto the same two factors (i.e., exploration and commitment) for all three scales (MEIM-R, MIM-Religion, MIM-Gender), suggesting commonality in the foundation of identity for all three domains (see also Schwartz et al., 2012). Further, the correlations among the three measures of group identity (ethnicity, gender, religion) demonstrated preliminary validity, as they suggest that participants with a stronger identification in one domain of identity also have stronger identification in the other two domains. In addition, correlations between the three identity measures and their respective group attitude composite scores add strength to the validity of using and adapted MEIM-R to measure identity in different domains because participants who were more strongly identified with the in-group also tended to see the in-group more positively (aligning with Social Identity Theory; Tajfel \& Turner, 1986).

While the majority of model indices showed good to acceptable fit, some failed to meet the criteria. Specifically, all chi-square difference tests were significant which might be explained by some limitations of our study. Further, the invariance of the factor structure of the MEIM-R and MIM-Religion could not be examined because the majority of the participants self-categorized as Christian (72\%) and/or Caucasian (86\%). It is possible that because the majority of the participants identified as members of these groups, our conclusions might also be limited to these groups. Future research that utilizes more diverse samples will be able to address this issue. In addition, because of the disproportionate numbers of participants of different ages (122 early adolescents, 65 middle adolescents, and 60 late adolescents), it would be inappropriate for us to conduct cross-sectional analyses of age differences in our variables, but believe this would be an important task for future research.

The findings of our study are preliminary, and more research is necessary to determine how well the MIM-Gender and MIM-Religion can measure adolescents' gender identity and religious identity. In the future, 
researchers should replicate the present study with additional samples. Most importantly, obtaining a larger and more diverse sample is needed, as this would improve our ability to further explore the psychometric properties of the adapted identity measures. Because this is a preliminary study, further research is needed on the reliability and validity (such as convergent and divergent validity) for scores on these measures. It is also important to note that while this study lends support to the validity and reliability of scores on the MIM-Gender and MIM-Religion to measure gender identity and religious identity (respectively), we did not explore the ability of the MEIM-R, MIM-Religion or MIM-Gender to validly measure identity development in any realm - a potential direction for future study.

\subsection{Conclusion}

Even with these limitations, our study provides valuable information about the measurement of adolescent group identity. The potential of using the MIM-Gender and MIM-Religion as a method to measure exploration and commitment in adolescents' gender and religious identities - in addition to the MEIM-R for ethnic identity (Phinney \& Ong, 2007) and the AIM for national identity (Schwartz et al., 2012) - may give researchers the ability to explore and compare adolescents' identities across different types of groups in an equivalent way (e.g., comparing someone's religious identity with his or her gender identity). This will make it possible for researchers to uniformly explore constructs related to group identity (e.g., group bias and prejudice, cognitive development, etc.) in relation to domains of identity assessed through an adolescent's exploration and commitment.

Further, by being able to measure group identity equivalently across groups, researchers will be better able to distinguish how other constructs interact with group identity in general and how they interact with identity specific to a certain type of group. For example, social identity theory posits that a stronger group identity will lead to more group bias (Tajfel \& Turner, 1986). With the ability to measure identity equivalently across groups, researchers will be able to determine if this is true of all types of groups, or if the relationship between identity and bias is stronger for some types of groups than others. Finally, researchers will also be able to better explore the way that different domains of identity - such as sexual orientation or political party - might interact with and influence each other (Narváez, Meyer, Kertzner, Ouellette, \& Gordon, 2009; Perry \& Pauletti, 2011).

\section{References}

Aboud, F. E. \& Doyle, A. B. (1993). The early development of ethnic identity and attitudes. In M. E. Bernal, \& G. P. Knight (Eds.), Ethnic identity: Formation and transmission among Hispanics and other minorities (1st ed., pp. 47-59). Albany, NY: State University of New York Press.

Ashdown, B. K., Hackathorn, J., \& Clark, E. M. (2011). In and out of the bedroom: Predictors of sexual satisfaction in the marital relationship. Journal of Integrated Social Sciences, 2, 40-57.

Ashmore, R. D., Deaux, K., \& McLaughlin-Volpe, T. (2004). An organizing framework for collective identity: Articulation and significance of multidimensionality. Psychological Bulletin, 130, 80-114. http://dx.doi.org/10.1037/0033-2909.130.1.80

Balistreri, E., Busch-Rossnagel, N. A., \& Geisinger, K. F. (1995). Development and preliminary validation of the Ego Identity Process Questionnaire. Journal of Adolescence, 18, 179-190. http://dx.doi.org/10.1006/jado.1995.1012

Bennion, L. D., \& Adams, G. R. (1986). A revision of the extended version of the objective measure of ego identity status: An identity instrument for use with late adolescents. Journal of Adolescent Research, 1 , 183-198. http://dx.doi.org/ 10.1177/074355488612005

Burton, J., Nandi, A., \& Platt, L. (2010). Measuring ethnicity: Challenges and opportunities for survey research. Ethnic and Racial Studies, 33, 1332-1349. http://dx.doi.org/10.1080/01419870903527801

Chavous, T. M., Rivas-Drake, D., Smalls, C., Cogburn, C., \& Griffin, T. (2008). Gender matters, too: The influence of school racial discriminations and racial identity on academic engagement outcomes among African American adolescents. Developmental Psychology, 44, 637-654. http://dx.doi.org/10.1037/0012-1649.44.3.637

Cohen-Malayev, M., Assor, A., \& Kaplan, A. (2009). Religious exploration in a modern world: The case of Modern-Orthodox Jews in Israel. Identity: An International Journal of Theory and Research, 9, 233-251. http://dx.doi.org/10.1080/15283480903344547

Diamond, L. M. \& Butterworth, M. (2008). Questioning gender and sexual identity: Dynamic links over time. Sex Roles, 59, 365-376. http://dx.doi.org/10.1007/s11199-008-9425-3 
Diamond, L. M., Pardo, S. T., \& Butterworth, M. R. (2011). Transgender experience and identity. In S. J. Schwarz, K. Luyckz, \& V. L. Vignoles (Eds.), Handbook of identity theory and research (pp. 629-648). New York, NY: Springer.

Dillon, F. R., Worthington, R. L., \& Moradi, B. (2011). Sexual identity as a universal process. In S. J. Schwarz, K. Luyckz, \& V. L. Vignoles (Eds.), Handbook of identity theory and research (pp. 649-6670). New York, NY: Springer.

Egan, S. K., \& Perry, D. G. (2001). Gender identity: A multidimensional analysis with implications for psychosocial adjustment. Developmental Psychology, 37, 451-463. http://dx.doi.org/10.1037/0012-1649.37.4.451

Erikson, E. H. (1950). Childhood and society. New York: Norton.

Gibbons, J. L. \& Ashdown, B. K. (2010). Ethnic identification, attitudes and group relations in Guatemala. Psychology, 1, 116-127. http://dx.doi.org/10.4236/psych.2010.12016

Greene, M. L., \& Way, N. (2005). Self-esteem trajectories among minority adolescents: A growth curve analysis of the patterns and predictors of change. Journal of Research on Adolescence, 15, 151-178. http://dx.doi.org/10.1111/j.1532-7795.2002.00090.x

Hill, J., \& Lynch, M. (1983). The intensification of gender-related role expectations during early adolescence. In J. Brooks-Gunn, \& A. Petersen (Eds.), Girls at puberty: Biological and psychosocial perspectives (pp. 201-228). New York: Plenum.

Hill, T. D., \& McCullough, M. E. (2008). Religious involvement and the intoxication trajectories of low income urban women. Journal of Drug Issues, 38, 847-862. http://dx.doi.org/0022-0426/08/03

Hu, L. T., \& Bentler, P. M. (1995). Evaluating model fit. In R. H. Hoyle (Ed.), Structural equation modeling: Concepts, issues, and applications (pp. 76-99). Thousands Oaks, CA: Sage.

Hunsberger, B., Pratt, M., \& Pancer, S. M. (2001). Adolescent identity formation: Religious exploration and commitment. Identity: An International Journal of Theory and Research, 1(4), 365-386. http://dx.doi.org/10.1207/S1532706XID0104_04

Kline, R. B. (2010). Principles and practice of structural equation modeling (3rd ed.). New York, NY: Guilford Press.

Kline, R. B. (2005). Principles and practices of Structural Equation Modeling. New York, NY: The Guilford Press.

Leak, G. K. (2009). An assessment of the relationship between identity development, faith development, and religious commitment. Identity: An International Journal of Theory and Research, 9, 201-218. http://dx.doi.org/10.1080/15283480903344521

Marcia, J. (1980). Identity in adolescence. In J. Adelson (Ed.), Handbook of adolescent psychology (pp. 159-187). New York: Wiley.

Meeus, W. (2011). The study of adolescent identity formation 2000-2010: A review of longitudinal research. Journal of Research on Adolescence, 21, 75-94. http://dx.doi.org/10.1111/j.1532-7795.2010.00716.x

Narváez, R. F., Meyer, I. H., Kertzner, R. M., Ouellette, S., \& Gordon, A. R. (2009). A qualitative approach to the intersection of sexual, ethnic, and gender identities. Identity: An International Journal of Theory and Research, 9, 63-86. http://dx.doi.org/10.1080/15283480802579375

Perry, D. G., \& Pauletti, R. E. (2011). Gender and adolescent development. Journal of Research on Adolescence, 21, 61-74. http://dx.doi.org/10.1111/j.1532-7795.2010.00715.x

Phillips, T. M. (2008). Age-related differences in identity style: A cross-sectional analysis. Current Psychology, 27, 205-215. http://dx.doi.org/10.1007/s12144-008-9035-9

Phinney, J. S. (1992). The multigroup ethnic identity measure: A new scale for use with diverse groups. Journal of Adolescent Research, 7, 155-176. http://dx.doi.org/10.1177/074355489272003

Phinney, J. S., \& Ong, A. D. (2007). Conceptualization and measurement of ethnic identity: Current status and future directions. Journal of Counseling Psychology, 54, 271-281. http://dx.doi.org/10.1037/0022-0167.54.3.271

Powlishta, K. K. (2004). Gender as a social category: Intergroup processes and gender-role development. In M. Bennett, \& F. Sani (Eds.), The development of the social self (pp. 103-134). New York: Psychology Press. 
Roberts, R. E., Phinney, J. S., Masse, L. C., Chen, Y. R., Roberts, C. R., \& Romero, A. (1999). The structure of ethnic identity of young adolescents from diverse ethnocultural groups. The Journal of Early Adolescence, 19, 301-322. http://dx.doi.org/10.1177/0272431699019003001

Schwartz, S. J., Park, I. J. K, Huynh, Q-L, Zamboanga, B. L., Umaña-Taylor, A. J., Lee, R., ... Agocha, V. B. (2012). The American Identity Measure: Development and validation across ethnic group and immigrant generation. Identity: An International Journal of Theory and Research, 12, 39-128. http://dx.doi.org/10.1080/15283488.2012.668730

Smith, T. W. (2007). Social identity and socio-demographic structure. International Journal of Public Opinion Research, 19, 380-390. http://dx.doi.org/10.1093/ijpor/edm015

Spencer, M., Icard, L., Harachi, T., Catalano, R., \& Oxford, M. (2000). Ethnic identity among monoracial and multiracial early adolescents. Journal of Early Adolescence, 20, 365-387. http://dx.doi.org/10.1177/0272431600020004001

Tajfel, H., \& Turner, J. (1986). The social identity theory of intergroup behavior. In S. Worchel, \& W. Austin (Eds.), Psychology of intergroup relations (2nd ed., pp. 7-24). Chicago: Nelson-Hall.

Tobin, D. D., Menon, M., Menon, M., Spatta, B. C., Hodges, E. V. E., \& Perry, D. G. (2010). The intrapsychics of gender: A model of self-socialization. Psychological Review, 117, 601-622. http://dx.doi.org/10.1037/a0018936

Williams, J. E., \& Best, D. L. (1982). Measuring sex stereotypes: A thirty-nation study. Beverly Hills, CA: Sage Publications.

Williams, J. E., Best, D. L., \& Boswell, D. A. (1975). The measurement of children's racial attitudes in the early school years. Child Development, 46, 494-500. http://dx.doi.org/10.2307/1128147

Yancey, A., Aneshensel, C., \& Driscoll, A. (2003). The assessment of ethnic identity in a diverse urban youth population. Journal of Black Psychology, 27, 190-208. http://dx.doi.org/10.1177/0095798401027002003

\section{Appendix A}

\section{Twelve Traits used to Measure Group Attitudes}

I. Negative Traits

1. Tells lots of lies

2. Can't be trusted

3. Is a coward

4. Gloomy/Looks on the bad side

5. Pouts a lot

6. Stuck up

II. Positive Traits

1. Unselfish

2. Giving

3. Cheerful and friendly

4. Accepts people who are different

5. Works well with others

6. Has a lot of honor and dignity

\section{Copyrights}

Copyright for this article is retained by the author(s), with first publication rights granted to the journal.

This is an open-access article distributed under the terms and conditions of the Creative Commons Attribution license (http://creativecommons.org/licenses/by/3.0/). 